\title{
Intergenerational professional relationships in elementary school teams: a social network approach
}

\author{
Kendra Geeraerts $^{\mathrm{a}}$, Piet Van den Bossche ${ }^{\mathrm{a}, \mathrm{b}}$, Jan $\operatorname{Vanhoof~}^{\mathrm{a}}$, Nienke Moolenaar ${ }^{\mathrm{c}}$ \\ ${ }^{a}$ University of Antwerp, Belgium \\ ${ }^{b}$ University of Maastricht, the Netherlands \\ ${ }^{c}$ University of Utrecht, the Netherlands
}

Article received 20 February / revised 22 August / accepted 22 August / available online 8 September

\begin{abstract}
This paper examines the extent to which school team members' professional relationships are affected by being part of a certain generational cohort. These professional relationships provide opportunities for intergenerational knowledge flows and can therefore be relevant for intergenerational learning. Nowadays these topics have gained more attention due to worldwide demographic changes such as increased retirement rates and high levels of teacher dropout. Data were gathered through a survey with socio-metric questions among 299 school team members in 15 elementary schools in the Netherlands. Using social network analysis, in particular 22 modelling, we analysed the effect of being part of a generational cohort on teachers' likelihood of having professional relationships in networks such as discussing work, asking and providing advice, and collaboration. Findings indicate that generational cohorts based on chronological age do matter in the formation of work related ties. These findings also support the importance of focusing on different professional networks since different age dynamics can be at play. Our findings also show that school team members of the youngest cohort tend to form intra-generational relationships, whereas older generational cohort members prefer inter-generational relationships. This study is innovative due to its application of social network analysis to investigate intergenerational knowledge flows.
\end{abstract}

Keywords: intergenerational learning; school teams; teacher development; social network analysis; p2 modelling 


\section{Introduction}

Nowadays, the role of knowledge management within schools as an organizational context has received more attention due to its potential to encourage innovative practices and to avoid knowledge loss within school teams (Thambi \& O'Toole, 2012). Knowledge loss can occur when workers leave the profession without sharing their knowledge or without turning implicit knowledge into an explicit mode. Similar to other countries, schools in The Netherlands are confronted with a large outflow of older teachers and a challenge to retain young teachers into the teaching profession. As compared to secondary school teams, elementary schools are often smaller organizations and characterized by a more cohesive organizational culture (Johnson, 1990). Also, the tasks of elementary school teachers show more similarities than for secondary school teachers. Therefore, we assume elementary school teams to be a fruitful context for exchange of knowledge which offers an interesting case to investigate how professional relationships are shaped. Facilitating intergenerational learning interactions seems to be a promising way to prevent knowledge loss within organizations (Gerpott, Lehmann-Willenbrock, \& Voelpel, 2016; Ropes, 2013; Starks, 2013). Intergenerational learning in school teams is mainly conceptualised as an interactive process between teachers of different generations that results in learning from one or both parties (Novotný \& Brücknerová, 2014; Ropes, 2011). In this study, we refer to generations of teachers by using the term generational cohort, which in turn refers to being born in the same chronological time period. Individuals of generational cohorts are found to possess different kinds of knowledge (Gerpott et al., 2016). Previous research within the context of school teams showed that teachers' knowledge varies depending on their generational cohort or level of experience. For instance, young teachers are perceived to possess innovative teaching methods and ICT skills, while teachers of the oldest generational cohort are perceived to have excellent classroom management skills and content knowledge (Geeraerts, Vanhoof, \& Van den Bossche, 2016). Simultaneously, classroom management skills are known to be a challenge for beginning teachers (Wolff, van den Bogert, Jarodzka, \& Boshuizen, 2015). These findings make age diversity and intergenerational learning within school teams relevant.

Moolenaar (2010) highlighted the importance of interactions between school team members to facilitate knowledge sharing and learning. Consequently, intergenerational knowledge sharing can be understood as a socio-constructive process in which interaction plays a facilitating role (Geeraerts et al., 2016; Novotný \& Brücknerová, 2014). This implies that school team members must be aware of resources such as information, knowledge and expertise of their colleagues, and make use of their social relationships to access these assets. Dynamics of sending and receiving professional relationships between or within generational cohorts have the potential to facilitate knowledge flows within school teams. These flows can be influenced by the fact that different generations of teachers also differ in life and work experiences or feelings. For example, a great number of early career teachers face a practice shock that is accompanied by feelings of uncertainty (Pillen, Beijaard, \& den Brok, 2013; Stokking, Leenders, De Jong, \& Van Tartwijk, 2003). In addition, young teachers fear being perceived as incompetent or vulnerable by their more experienced colleagues, also described as feeling evaluated (Kelchtermans \& Ballet, 2002). On the contrary, older teachers or experienced teachers are perceived to have a high level of self-confidence in their profession (Geeraerts et al., 2016). Consequently, we expect that teachers of different generations show differences in the formation of professional relationships.

In this study, we examine the formation of relationships in elementary school teams in The Netherlands, focusing on discussing work, asking and providing advice, and collaboration. We label these relationships as professional relationships and question them from an intergenerational perspective, meaning that these relationships can be formed within or across different generations of school team members. Hereto, we apply methods from Social Network Analysis (SNA) enabling us to investigate social relationships and to look more deeply into interactions among school team members. When investigating professional relationships we focus on sending and receiving relationships. Specifically, this study investigates to what extent school team members of different generational cohorts differ in the number of 


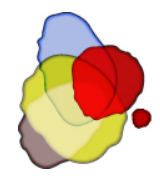

professional relationships they send and receive, and secondly, how being part of the same generational cohort affects the likelihood of engaging in professional relationships. In the following, we start with framing our work within the literature of generations, and school team members' social relationships. The latter part builds on social capital theory and social network theory.

\section{Theoretical framework}

\subsection{Generational diversity among school team members}

The concept of generations was first introduced by Mannheim (1952) and referred to a generation as a group of individuals who share mutual social and historical events during their lifespan. According to Edge (2014) school teams include three generations of teachers and leaders: Baby Boomers (1946-65), Generation X (1966-80) and Generation Y (1981-2003). In literature, there are a lot of inconsistencies concerning the labels of these generational cohorts and the boundaries used to determine a generational cohort. Brücknerová and Novotný (2016) relied in their study on intergenerational learning of teachers on teachers' own perceptions of themselves as a member of a particular generation. Most studies used the chronological dimension of age to frame school team members' generational cohorts (Edge, Descours, \& Frayman, 2016; Geeraerts et al., 2016).

Looking at school teams through a generational lens sheds light on the level of age diversity within school teams (Brücknerová \& Novotný, 2016). Previous studies in other contexts have already recognized the benefits of age diversity in teams since individuals contribute different kinds of information, knowledge, skills, and expertise to the team (Gerpott, Lehmann-Willenbrock, \& Voelpel, 2016; Williams \& O'reilly, 1998). The traditional point of view in which older workers are perceived as experts is questioned nowadays. Fuller and Unwin (2004) acknowledged that young workers have already developed different kinds of knowledge and skills, and also have higher educational levels than many of their older counterparts with whom they interact in the workplace. This finding brings the importance of the bidirectional character within the learning process under attention. Previous research by Geeraerts et al. (2016) showed that teachers of different generational cohorts are perceived to possess different kinds of knowledge. Whereas young teachers were seen as a knowledge source for innovative teaching methods and ICT skills, teachers older than 50 were rather associated with classroom management skills and subject knowledge. Many studies have focused on differences between novice teachers and experienced ones (Wolff et al., 2015), but studies in which the interactions between both parties are investigated are rather scarce.

Thus, interactions between teachers of different generations can provide opportunities to learn from each other's knowledge, especially when these learning processes are characterized by bidirectional interactions instead of unidirectional ones. These findings underline the added value of the formation of relationships across different generations of teachers for the construction and transfer of knowledge, and raises important questions on knowledge management within school teams.

\subsection{The social side of learning across generations}

In this paper, we argue that professional relationships between teachers of different generations may provide opportunities to learn from each other. This notion builds on a more 'social' interpretation on how learning takes place. Lee et al. (2004) highlight that learning is a complex concept due to different approaches to learning. The traditional approach to learning describes 'learning as acquisition' and builds on cognitive psychology and behaviourism (Sfard, 1998). This learning as acquisition approach focusses mainly on the individual. A more recent approach refers to 'learning as social participation' and focusses on learning 


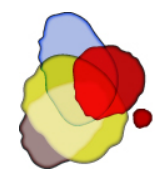

through social relations and participation of individuals within communities of practice (Lave \& Wenger, 1991; Sfard, 1998). This implies that learning can be understood as a social, interactive process of coconstruction. Learning in the workplace is mainly informal and involves learning from colleagues on the job (Eraut, 2004). Knowledge acquisition and access to information from others are equally important contributors to learning processes in workplaces (Ashton, 2004). Therefore, many researchers in the field of workplace learning emphasize the importance of social relationships for informal learning (Doornbos, Bolhuis, \& Simons, 2004; Eraut, 2004; Tynjälä, 2008). Also in terms of teacher learning, the social side of learning is emphasised based on the idea that cognition is situated in nature (e.g. Kwakman, 2003; Lohman, 2000, 2006; Meredith, Van den Noortgate, Struyve, Gielen, \& Kyndt, 2017; Van Waes, Van den Bossche, Moolenaar, De Maeyer \& Van Petegem, 2015). A shift from a focus on the individual towards a more social approach contributed to the popularity of social network research methods to investigate relationships of teachers (Baker-Doyle, 2015). We will now further explore how knowledge sharing among generational cohorts may contribute to intergenerational learning by first zooming into teachers' relationships, and then, into some relevant social network concepts and dynamics.

\subsection{School team members' social relationships}

The attention for social relationships between teachers is underpinned by research on the importance of social capital for school improvement and instructional reform (Spillane, Kim, \& Frank, 2012). Social capital within an organization reflects an investment in social relationships through which valuable resources such as knowledge, information and expertise can be accessed, borrowed, or leveraged (Daly, 2010; Lin, 1999). The general concept of social capital provides a framework to conceptualize how individuals have access to resources (e.g. information, expertise) by the web of social relationships surrounding them, thereby offering (or hindering) opportunities for (intergenerational) learning.

Borgatti, Everett, and Johnson (2013) distinguish two main types of relations: relational states and relational events. Relational states refer to continuously persistent relationships between individuals (e.g. being a colleague, teacher or friend), whereas relational events refer to discrete events such as interactions (e.g. asking a colleague for advice). The outcomes of interactions are flows, and can contain, for instance, information, knowledge, and expertise (Borgatti et al., 2013). We build on earlier work, suggesting that social relationships offer opportunities for knowledge creation, knowledge retention, and knowledge transfer (Argote, McEvily, \& Reagans, 2003). In school teams, collegial relationships have the potential to initiate occasions to learn from each other within or between generational cohorts. Informal learning interactions between teachers occur in the form of engaging in dialogue, collaborating, sharing resources such as information, lesson materials, ideas, advice, etc. (Baker-Doyle, 2015; Kwakman, 2003; Lohman, 2006). Accordingly, knowledge flows are the result of interactions between two teachers through which information is exchanged.

In addition, social relationships can be described in terms of the content of the relationship. Ibarra (1993, 1995) distinguishes between expressive and instrumental relationships. This distinction also applies to school teams (Moolenaar, 2010). Whereas expressive relationships do not directly aim at work related issues (e.g. friendship), instrumental relationships do aim to achieve organisational goals. For instance, work related discussions and asking questions are interactions that enable exchange of expertise (Gerpott et al., 2016). Furthermore, Spillane et al. (2012) see advice and information seeking relationships as critical for teachers' professional development and for knowledge development. Also, relationships in terms of teacher collaboration can be seen as an indicator of informal learning within school teams (Richter, Kunter, Klusmann, Lüdtke, \& Baumert, 2011). All of these relationships: discussing work, asking advice, providing advice, and collaboration, provide opportunities for intergenerational learning and can be labelled as instrumental (Geeraerts et al., 2016; Novotný \& Brücknerová, 2014). Moolenaar (2010) found only partial overlap between these different networks, which highlights the semi-unique character of these networks as a source for exchange of knowledge, expertise, teaching materials, and other resources valuable to teacher 


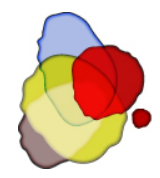

learning and school performance. This study focuses on instrumental relationships and labels them as professional relationships due to its professional nature and closer link to organisational benefits.

Taken together, professional relationships among school team members are essential since they provide access to social resources such as knowledge, information, and expertise. School team members can only benefit from these resources when they have access to them through social interactions, and these interactions are facilitated by social relationships. A research method that allows us to investigate the formation of school team members' relationships is social network analysis. In the following, we discuss degree centrality and network homophily as two important network concepts.

\subsection{Social network concepts and dynamics}

\subsubsection{Degree centrality}

Social network research has the potential to reveal the underlying network structure in an organization so that more insight in the exchange of resources within an organization can be established (Cross, Parker, \& Borgatti, 2002). In this study, networks are represented by school teams in which school team members are the actors or nodes. Centrality is a commonly used concept within social network research that focuses on the position of a node or actor within a network (Borgatti et al., 2013). The concept of centrality identifies the structural importance of a node, by looking at how many connections or relations one node has to other nodes. Within social network research, these relationships are often referred to as ties. Since our study aims to investigate relationships, we do not approach our data from the perspective of centrality as such, but rather from the perspective of interactions, measured by degree centrality.

Degree centrality is a frequently used measure for relationships within networks, and it refers to the number of ties a node has to other nodes. In a directed graph or network, degree centrality has two types: indegree and outdegree (Borgatti et al., 2013). Indegree centrality involves the number of incoming ties of an actor within a network. It can be seen as a measure of individual popularity (in the case of a positive tie network), since this measure is the number of colleagues by whom the respondent, or school team member, was nominated. Outdegree centrality counts the number of outgoing ties of an actor within a network. It involves the number of colleagues nominated by the respondent, or school team member, which suggests a measure of individual activity (Borgatti et al., 2013). Consequently, degree centrality refers to the individual node level. A normalized in- and outdegree score can be interpreted as the percentage of relationships that school team members maintain within the whole network.

We focus on the calculation of degree centrality within the networks of discussing work, asking and providing advice, and collaboration, since these networks can be seen as a potential indicator of learning within school teams. Moreover, we assume that there might be differences in degree centrality between different generational cohorts. For instance, Kelchtermans (2006) mentioned that asking for advice from a colleague might be seen as a request for help, which is accepted for young or beginning teachers but not for experienced ones. This might imply that teachers of the youngest cohort are more likely to form more ties to ask advice than teachers of the older generational cohorts. Spillane et al. (2012) see advice and information relationships as critical for teachers' professional development and for knowledge development. In their study, more experienced teachers were less likely to receive advice and information from other colleagues, as compared to early career teachers (Spillane et al., 2012). In terms of teacher collaboration, previous research of Richter et al. (2011) showed that young teachers tend to collaborate more frequently than older colleagues. Teacher collaboration seems to decrease with age (Richter et al., 2011). Regarding work related conversations, beginning teachers are more likely to interact with colleagues in order to overcome professional challenges and to exchange teaching ideas, as compared to experienced colleagues (Grangeat \& Gray, 2007). 


\subsubsection{Network homophily}

The concept of network homophily, often referred to by the proverbial expression 'birds of a feather flock together', captures the idea that individuals are more likely to have ties with others who are similar to themselves on attributes such as age, race, gender, education, and values, than with individuals that are dissimilar to them (Feld, 1982; McPherson, Smith-Lovin, \& Cook, 2001). A study of Marsden (1988) revealed that the greater the age difference between individuals, the less likely they were to discuss important matters with each other. In particular, the youngest age cohorts tend to have confiding relationships with individuals of their own cohort.

Whereas degree centrality focused on the individual level, network homophily refers to similarities between individuals and therefore focuses on the dyad level within networks. These dyads can be mutual, asymmetric or null dyads (Wasserman \& Faust, 1994). In mutual dyads, actors within the network choose each other; ties are reciprocated. An asymmetric dyad refers to a one-directional tie in which one actor chooses the other actor, without being reciprocal. A null dyad indicates the absence of a tie between two actors. When dyads occur between actors with similar attributes, in our case being part of the same generational cohort, this can be labelled as homophily.

Individuals with similar background characteristics are more likely to have mutual experiences which in turn results in shared knowledge (Reagans \& McEvily, 2003). According to Reagans and McEvily (2003) this common knowledge has a positive effect on knowledge transfer. Therefore, we expect that teachers of the same generational cohort are more likely to engage in work related or so-called instrumental interactions. This concept of network homophily is also supported by the ideas of social identity theory (Tajfel \& Turner, 1986). This theory follows a similar reasoning, suggesting that individuals have more positive perceptions towards people who are similar to them, compared to people who are dissimilar. This results in categorizations of in ("us") and out ("them") groups. Within work-group diversity research, Williams and O'reilly (1998) referred to this way of categorizing as a social categorization perspective. Similarity of age characteristics can be seen as a trigger for these in- and out-group categorizations (Dencker, Joshi, \& Martocchio, 2007).

Consequently, teachers might be more likely to form ties with colleagues of the same generational cohort. This implies that resources such as information and knowledge tend to flow within the particular generational cohort. Following this reasoning, both outgoing and incoming relationships, also referred to as ties of sender and receiver, occur within a generational cohort rather than between different generational cohorts.

\section{Research questions}

We investigate whether belonging to a certain generation affects individual school team members' likelihood of having relationships in networks through which resources can flow. More specifically, we focus on four instrumental networks, referring to professional relationships in which school team members discuss their work, receive or provide advice, and collaborate, since these relationships can be relevant for learning in school teams (Geeraerts et al., 2016; Novotný \& Brücknerová, 2014). Therefore, the following research questions are set forward:

RQ1: To what extent do school team members of different generational cohorts differ in the number of professional relationships (indegree and outdegree; sending and receiving relationships)?

RQ2: To what extent does being part of the same generational cohort affect the likelihood of engaging in professional relationships within school teams (network homophily)? 


\section{Methodology}

\subsection{Sample}

The data from this study was collected at 15 elementary schools in The Netherlands. The data collection was part of a larger project on school improvement in The Netherlands in which 53 schools participated. All schools were organised as a cluster of Catholic schools, supported by a single Catholic school board. We selected the subsample of schools based on the following criteria: school team size was 10 or more teachers, and in each school, each generational cohorts was represented by at least $20 \%$ of the respondents. This resulted in a final selection of 15 schools, which enabled us to investigate intergenerational relationships in schools where all generational cohorts were sufficiently represented. The sample consisted of all principals and teachers, including instructional coaches (teachers with specialised instructional tasks, such as emotional/behavioral support), since we wanted this selection to be as close as possible to the core teaching team. The sample did not include temporary and replacement teachers. The overall sample contained 284 teachers and 15 school principals $(n=299)$.

Generational cohorts are based on chronological age. Within this sample, three generational cohorts can be distinguished. The 'young' cohort contained 94 educators aged 35 years old or younger. The 'middle' cohort contained 87 educators from 36 to 50 years old. The 'old' cohort consists of 118 teachers older than 50 years. Most school members (75\%) were female. The sample demographics are summarized in Table 1.

Table 1

Sample demographics $(\mathrm{n}$ schools $=15, \mathrm{n}$ respondents $=299)$

\begin{tabular}{|c|c|c|c|c|c|}
\hline & Categories & Teachers & Principals & $\begin{array}{l}\text { Total number of } \\
\text { school team } \\
\text { members }\end{array}$ & Percentage \\
\hline \multirow[t]{3}{*}{ Generational cohort } & Young cohort (-36 yrs) & 93 & 1 & 94 & $31 \%$ \\
\hline & $\begin{array}{l}\text { Middle cohort }(36-50 \\
\text { yrs })\end{array}$ & 84 & 3 & 87 & $30 \%$ \\
\hline & Old cohort $(50+$ yrs $)$ & 107 & 11 & 118 & $39 \%$ \\
\hline \multirow[t]{2}{*}{ Gender } & Male & 63 & 11 & 74 & $25 \%$ \\
\hline & Female & 221 & 4 & 225 & $75 \%$ \\
\hline Total number & & 284 & 15 & 299 & $100 \%$ \\
\hline
\end{tabular}

\subsection{Data collection}

The survey included questions on job satisfaction, leadership, school team, strategy and policy, processes, citizenship in the classroom and general questions. The section on 'school team' contained sociometric questions that questioned the social networks within the school team. Network questions used in this study were: 
- Discussing work: Whom do you turn to in order to discuss your work?

- Asking advice: Whom do you prefer to go to for work related advice?

- Providing advice: To whom do you give work related advice?

- Collaboration: With whom do you like to collaborate the most?

To answer these socio-metric questions, respondents were provided with a list of their school team members. According to Marsden (2011), this list helps respondents to remind the alters in their network and so it also minimizes measurement error. In order to contribute to the premise of anonymous analysis of the data, the alter list contained a letter code for each alter (e.g. Jessica Thompson $=$ AB). Respondents were asked to indicate this letter code by completing the survey instead of mentioning the name and surname of the alter. There was no limitation to the number of colleagues a respondent could indicate as part of his/her network. An example of the visualization of a school team network is displayed in Figure 1.

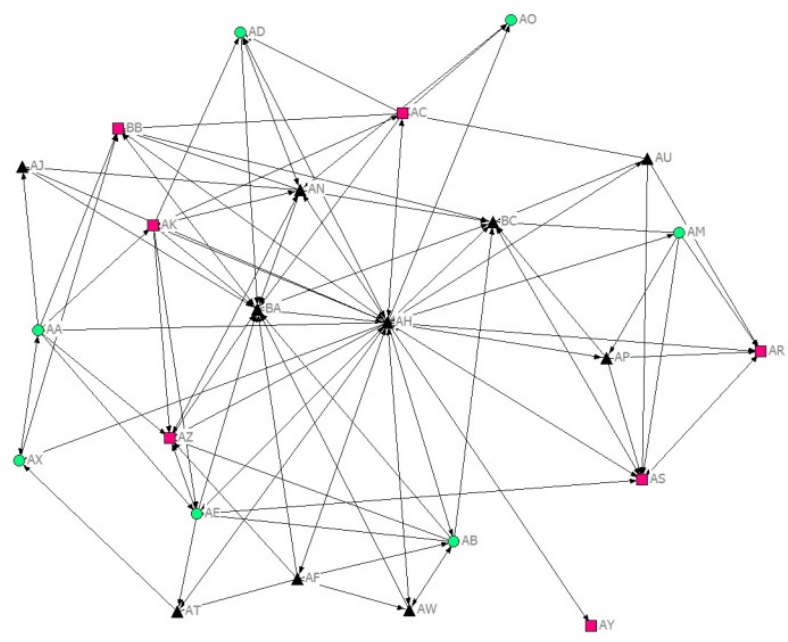

Figure 1. Example of 'asking advice' network. ${ }^{1}$

\subsection{Measures}

Our dependent variable is the existence or the absence of a professional relationship between two school team members (a dyad). Concretely, for every pair of school team members $i$ and $j$, a value of 1 represents a relationship between $i$ and $j$. For instance, $i$ provides advice to $j$. A value of 0 indicates the absence of a tie between $\mathrm{i}$ and $\mathrm{j}$. The mathematical representation of these relationship is an adjacency matrix composed by 0s and 1s (Van Duijn \& Vermunt, 2006).

\subsubsection{Individual level measures involve characteristics of the individual school team members.}

\section{Generational cohort}

In line with the findings of a study by Richter et al.(2011), based on Spearman's correlation we found a high correlation between age and the number of years of teacher experience within education or within the school, $\mathrm{r}=0.84$ and $\mathrm{r}=0.52$ respectively. This implies that these measures are nearly interchangeable and suggests that the number of teachers who enter the teaching profession at later stages in their life is limited. Consequently, we only take into account the variable of generational cohort based on chronological age.

This measure refers to three age related categories: young, middle and old cohort. In the survey, teachers were asked to indicate their age $(1=20-25$ years, $2=26-30$ years, $3=31-35$ years, $4=36-40$ years,

\footnotetext{
${ }^{1}$ the youngest cohort is represented by circles, the middle cohort by squares, and oldest cohort by triangles
} 
$5=41-45$ years, $6=46-50$ years, $7=51-55$ years, $8=$ older than 55 ). These age categories were first recoded into three categories that are in line with generational cohorts that can be found in the literature under the labels of Generation Y, Generation X, and the Baby Boomers generation (young $=20-35$ years, middle $=36$ 50 years, old $=51$ and older) (Edge, 2014; Geeraerts et al., 2016; Glass, 2007; Novotný \& Brücknerová, 2014). Consequently, this categorical variable contains three categories that each cover approximately 15 years. Finally, two dummy variables were generated, in which 'middle' and 'old' were contrasted with the 'young' cohort.

\section{Gender}

This individual feature is coded in the following way: a value of 0 refers to male school team members, and a value of 1 refers to female school team members.

\section{Function}

This measure takes a value of 0 for a teacher position, and a value of 1 for a principal position.

\subsubsection{Dyadic level measures, also named relationship covariates.}

\section{Generational cohort similarity}

Three dummy variables of a generational cohort are used: youngest cohort, middle cohort, oldest cohort. The 'absolute difference' function in the p2 module is used to investigate the likelihood of a relationship when actors are part of a different generational cohort, in other words, not being part of the same generational cohort.

\subsection{Data analysis}

In order to respond to RQ1, social network properties at the individual level were calculated by using software package UCINET 6.0 (Borgatti et al., 2013). Normalized degree centrality, both indegree and outdegree, was calculated. These measures can be interpreted as percentages. Consequently, these normalized in- and outdegree scores have a value from 0 to 100 , in which 0 indicates the absence of relationships, and 100 refers to being tied to the entire school team. The variations in the percentages of incoming and outgoing relationships are provided by the standard deviations of the normalized in- and out degree measures. In addition, the statistical software program IBM SPSS 24 was used to measure the effects of individual node characteristics on the network properties as a dependent variable. A one-way Analysis of Variance (ANOVA) was conducted on each network question. For comparisons of the mean scores among the different generational cohorts, the post hoc test Tukey with its significant difference procedure $(\alpha=0.05)$ was used.

Regarding RQ2, we used the p2 package within the social network software Stocnet (Boer et al., 2006). By using p 2 modelling, we investigated dyadic ties as the dependent variable. Dyadic level factors focus on similarities and differences.

The p2 model is a model for the statistical analysis of directed binary relationship data with actor and/or dyadic covariates (Boer et al., 2006; Zijlstra \& van Duijn, 2003). As such, a p2 model is designed to predict the likelihood of the formation of social relationships (e.g. work discussions) between pairs of actors (e.g. teachers and principals) based on individual and dyadic variables (e.g. belonging to a generational cohort (Boer et al., 2006; Zijlstra \& van Duijn, 2003). P2 models can be seen as a type of logistic regression model that takes the dependency between relationships from one to another actor into account (Lazega \& van Duijn, 1997). Ordinary logistic regression models cannot be used here since the assumption of data independence is violated. P2 modelling specifically focusses on complete, directed networks, which implies that every actor within the network can have ties with all other actors. However, the model can handle (some) missing data (Van Duijn \& Vermunt, 2006). The multilevel variant of the p2 model is an extension of the p2 model which can be used for the analysis of multiple networks. Parameter estimates of the p2 model 
and the multilevel p2 model derive from the Markov Chain Monte Carlo (MCMC) procedures which are integrated in the p2 module of the social network analysis software StOCNET (Boer et al., 2006; Zijlstra, Van Duijn, \& Snijders, 2006).

The p2 model is designed to compute the likelihood of sending a relationship (cf. out-degree; called sender effect), receiving a relationship (cf. in-degree; called a receiver effect), and the likelihood of engaging in a relationship based on dyadic similarity (cf. homophily; called a reciprocity effect). A positive significant parameter estimate indicates a positive effect of the variable on the likelihood to form a relationship. For example, a positive significant sender effect of gender (male/female) indicates that female teachers have a higher likelihood to send relationships within the network than male teachers. In order to investigate homophily effects, the $\mathrm{p} 2$ software constructs dyadic matrices based on the absolute difference between two actors within the network. For instance, a dyad between a school team member of the youngest generational cohort and a school team member of the middle generational cohort represents a relationship between school team members of a different generational cohort. This absolute difference between being part of the youngest and oldest cohort (dummy variable $=0$ ) and being part of the middle cohort (dummy variable $=1$ ) is 1 . In this example, a negative parameter estimate would suggest that a difference in generational cohort is related to a lower likelihood of having relationships. Consequently, a negative parameter suggests that relationships between members of the same generational cohort are more likely to occur. As such, a negative reciprocity effect signals the existence of a homophily effect.

Regarding the significance level of the parameter estimates, the p2 output in Stocnet does not directly provide this information. An additional Wald test needs to be calculated by dividing the parameter estimate by the standard error of the estimator. When the ratio is smaller than -2 or larger than 2 , a significant effect occurs at 0.05 level.

\section{Findings}

\subsection{To what extent do generational cohorts differ in the number of professional relationships?}

The first part of the study investigated if teachers of different generational cohorts show differences in degree centrality measures of the network questions. A one-way Analysis of Variance (ANOVA) was conducted on each network question. The independent variable contained the generational cohorts and the dependent variable contained indegree centrality and outdegree centrality.

\subsubsection{The number of outgoing professional relationships}

No significant generational cohort differences were found with regard to normalized outdegree centrality measures of the networks, as displayed in Table 2. This implies that school team members of different generational cohorts do not significantly differ statistically, with regard to the average number of sending ties within the networks of discussing work, asking advice, providing advice, and collaboration. 
Table 2

Anova of normalized outdegree $(N=15, n=299)$

\begin{tabular}{lllllllll}
\hline & \multicolumn{3}{l}{ Young (1) } & \multicolumn{2}{l}{ Middle (2) } & Old (3) & \multicolumn{3}{c}{$\begin{array}{l}\text { ANOVA main } \\
\text { effect }\end{array}$} \\
\hline & $\mathrm{M}$ & $S D$ & $\mathrm{M}$ & $S D$ & $\mathrm{M}$ & $S D$ & $\mathrm{~F}$ & $\mathrm{p}$ \\
\hline Discussing work & 0.32 & 0.19 & 0.33 & 0.22 & 0.27 & 0.19 & 2.448 & 0.088 \\
Asking advice & 0.20 & 0.15 & 0.17 & 0.14 & 0.16 & 0.13 & 2.304 & 0.102 \\
Providing advice & 0.20 & 0.19 & 0.22 & 0.23 & 0.19 & 0.19 & 0.460 & 0.632 \\
Collaboration & 0.27 & 0.20 & 0.27 & 0.24 & 0.25 & 0.22 & 0.362 & 0.697 \\
\hline
\end{tabular}

\subsubsection{The number of incoming professional relationships}

Regarding normalized indegree centrality, the main effect analysis found a statistically significant generational cohort difference in the network question 'providing advice' $[F(2,297)=9.003, p=0.000]$ and the network question 'collaboration' $[\mathrm{F}(2,297)=9.367, \mathrm{p}=0.000]$. No significant differences were found for the networks of 'discussing work' and 'asking advice'. Descriptives of the mean values for the normalized indegree of the generational cohorts are displayed in Table 3.

Table 3

Anova of normalized indegree $(N=\mathbf{1 5}, \boldsymbol{n}=\mathbf{2 9 9})$

\begin{tabular}{lllllllllll}
\hline & Young (1) & Middle (2) & Old (3) & & ANOVA main effect & $\begin{array}{l}\text { Post hoc } \\
\text { Tukey }\end{array}$ \\
\hline & & & & & & & & & & \\
& & & & & & & & \\
& 0.32 & 0.21 & 0.29 & 0.17 & 0.30 & 0.19 & 0.530 & 0.589 & \\
\hline $\begin{array}{l}\text { Discussing work } \\
\text { "being chosen to discuss work } \\
\text { with" }\end{array}$ & & & & & & & & & \\
$\begin{array}{l}\text { Asking advice } \\
\text { "being asked for advice" }\end{array}$ & 0.16 & 0.18 & 0.18 & 0.16 & 0.18 & 0.16 & 0.633 & 0.532 & \\
$\begin{array}{l}\text { Providing advice } \\
\text { "being provided with advice" }\end{array}$ & 0.24 & 0.14 & 0.21 & 0.12 & 0.17 & 0.12 & $9.003^{* *}$ & 0.000 & $1>3 * *$ \\
$\begin{array}{l}\text { Collaboration } \\
\text { "being chosen to collaborate with" }\end{array}$ & 0.32 & 0.18 & 0.25 & 0.12 & 0.23 & 0.14 & $9.367^{* *}$ & 0.000 & $1>3 *$ \\
\hline
\end{tabular}

* significant at 0.05 level

** significant at 0.01 level

The post hoc test Tukey with its significant difference procedure $(\alpha=0.05)$ was used for comparisons of the mean scores among the different generational cohorts. Regarding the indegree of 'providing advice', members of the youngest cohort $(\mathrm{M}=0.24, \mathrm{SD}=0.14)$ were found to have significantly higher ratings than members of the oldest cohort $(\mathrm{M}=0.17, \mathrm{SD}=0.12)$. This implies that the youngest school team members 
receive advice from more colleagues than the members of the oldest generational cohort do. Whereas young school team members are tied to on average $24 \%$ of the network, the oldest cohort is tied to on average $17 \%$ of the school team. There were no statistically significant differences found between the other generational cohorts in terms of indegree on giving advice.

Regarding the indegree of 'collaboration', the youngest group of team members $(\mathrm{M}=0.32, \mathrm{SD}=0.18)$ was found to have significantly higher scores than members of the middle and oldest cohorts $(M=0.25$, $\mathrm{SD}=0.12$; and $\mathrm{M}=0.23, \mathrm{SD}=0.14$, respectively). This implies that the youngest team members are chosen by more colleagues to collaborate with, as compared to the two older generational cohorts. Young school team members form ties with on average $32 \%$ of their network, in contrast to $25 \%$ for the middle cohort and $23 \%$ for the oldest cohort.

The above described ANOVA analysis and findings provide insight in the average number of outgoing and incoming ties, however, insight in which generational cohort sends ties to and receives ties from which cohort is missing. In addition, the ANOVA did not control for gender and function, which might give a different picture of sending and receiving ties. Also, the occurrence of a homophily effect could not be tested by the previous analysis. Therefore, we ran the $\mathrm{p} 2$ analysis to further our understanding in these dynamics. Parameter estimates of the multilevel p2 models for investigating the effect of individual and dyadic level demographics on the likelihood of having relationships within the networks of discussing work, asking advice, providing advice, and collaboration, are presented in Table 4. 
Table 4

The effect of sender and receiver demographic variables on the likelihood of having relationships within the networks of discussing work, asking advice, providing advice, and collaboration. Parameter estimates of the multilevel p2 models. $(n=299)$

\begin{tabular}{|c|c|c|c|c|}
\hline \multirow[t]{2}{*}{ Network } & \multirow{2}{*}{$\begin{array}{l}\text { Discussing work } \\
\text { PE (SE) }\end{array}$} & \multirow{2}{*}{$\begin{array}{l}\text { Asking advice } \\
\text { PE (SE) }\end{array}$} & \multicolumn{2}{|c|}{ Providing advice Collaboration } \\
\hline & & & PE (SE) & PE (SE) \\
\hline \multicolumn{5}{|l|}{ Overall effects } \\
\hline Density & $-\mathbf{1 . 9 8}(0.22)$ & $-\mathbf{2 . 1 2}(0.15)$ & $\mathbf{- 2 . 5 1}(0.22)$ & $-2.17(0.25)$ \\
\hline Reciprocity & $2.63(0.18)$ & $2.21(0.17)$ & $2.11(0.18)$ & $2.21(0.21)$ \\
\hline \multicolumn{5}{|l|}{ Sender covariates } \\
\hline Middle cohort & $0.10(0.21)$ & $-0.36(0.22)$ & $0.40(0.23)$ & $0.29(0.27)$ \\
\hline Old cohort & $-0.28(0.18)$ & $\mathbf{- 0 . 3 9}(0.13)$ & $\mathbf{0 . 4 7}(0.19)$ & $0.15(0.21)$ \\
\hline Gender & $0.20(0.15)$ & $0.00(0.00)$ & $0.25(0.18)$ & $0.25(0.21)$ \\
\hline Function & $-0.09(0.31)$ & $0.62(0.33)$ & $-0.06(0.30)$ & $\mathbf{0 . 8 6}(0.36)$ \\
\hline \multicolumn{5}{|l|}{ Receiver covariates } \\
\hline Middle cohort & $-0.16(0.19)$ & $0.28(0.12)$ & $-\mathbf{0 . 3 7}(0.14)$ & $\mathbf{- 0 . 4 4}(0.17)$ \\
\hline Oldest cohort & $-0.08(0.16)$ & $0.07(0.15)$ & $\mathbf{- 0 . 6 0}(0.13)$ & $\mathbf{- 0 . 5 5}(0.14)$ \\
\hline Gender & $0.15(0.17)$ & $0.00(0.00)$ & $0.24(0.13)$ & $0.21(0.14)$ \\
\hline Function & $1.35(0.29)$ & $\mathbf{0 . 9 7}(0.21)$ & $-0.38(0.25)$ & $-0.17(0.28)$ \\
\hline \multicolumn{5}{|c|}{ Relationship covariates } \\
\hline Youngest cohort & $\mathbf{- 0 . 2 1}(0.06)$ & $\mathbf{- 0 . 1 8}(0.08)$ & $-0.15(0.08)$ & $\mathbf{- 0 . 1 5}(0.07)$ \\
\hline Middle cohort & $0.01(0.07)$ & $0.08(0.08)$ & $0.03(0.09)$ & $0.10(0.08)$ \\
\hline Oldest cohort & $-0.10(0.06)$ & $-0.08(0.07)$ & $-0.04(0.08)$ & $-0.09(0.07)$ \\
\hline \multicolumn{5}{|l|}{ Random effects } \\
\hline Sender variance & $1.19(0.15)$ & $\mathbf{0 . 7 2}(0.11)$ & $\mathbf{0 . 5 4}(0.18)$ & $1.78(0.22)$ \\
\hline Receiver variance & $1.06(0.13)$ & $1.18(0.16)$ & $\mathbf{0 . 3 6}(0.08)$ & $\mathbf{0 . 6 8}(0.11)$ \\
\hline Covariance & $\mathbf{- 0 . 7 8}(0.12)$ & $\mathbf{- 0 . 6 2}(0.11)$ & $\mathbf{- 0 . 5 8}(0.11)$ & $\mathbf{- 0 . 7 1}(0.13)$ \\
\hline
\end{tabular}

Note: $\mathrm{PE}=$ parameter estimate; $\mathrm{SE}=$ standard error; bold typeface refers to a significant $\mathrm{PE} ; \mathrm{N}=9309$ dyadic relations from 299 school team members in 15 elementary schools 
First of all, overall effects show negative density effects and positive reciprocity effects within the four networks. These findings suggest that the networks are overall rather sparse, meaning that the likelihood of having a tie is lower than $50 \%$ for the reference group, which are dyads of young male teachers. The positive parameter estimates of reciprocity indicate a tendency of reciprocated ties instead of unidirectional ties throughout the different networks. With regard to the random effects, the positive and significant effects of sender and receiver variance indicate that there is considerable variation among school team members in the amount of ties they send and receive within the four networks. The negative sender-receiver covariance suggests that school team members who report to send more ties have a lower likelihood of receiving ties within their network, when allowing for differences between schools.

\subsubsection{The likelihood to send professional relationships}

Looking at the sender covariates, we found no significant effects for the network discussing work. In other words, none of the individual characteristics affected the likelihood of sending ties in a positive or negative way. More specifically, school team members of the middle or oldest cohort did not send more ties than young school team members, female not more than male, and school principals not more than teachers. Within the other three networks, results indicated that some of the individual characteristics affected the likelihood of sending relationships. Within the network of asking advice, being part of the oldest cohort decreases the likelihood of asking advice. In addition, the oldest cohort tends to send significantly more relationships of providing advice. Within the network of collaboration, results reveal that being a school principal increases the likelihood of sending collaboration ties.

\subsubsection{The likelihood to receive professional relationships}

Regarding the receiver covariates, significant effects were found in all the four networks. Being a school principal increases the likelihood of receiving relationships in discussing work and asking advice networks. Also, being part of the middle cohort increases the likelihood of receiving relationships in the network of asking advice. This implies that principals and teachers of the middle cohort are more likely to be sought out for advice. In addition, the network of 'providing advice' shows that teachers of the middle and oldest cohort have a lower likelihood to receive advice relationships. The same trend can be found within the network of collaboration. Both individual characteristics, being part of the middle and being part of the oldest cohort, decreases the likelihood of receiving collaboration ties. For both networks, providing advice and collaboration, the effect of being part of the oldest cohort is stronger than the middle cohort. This suggests that being part of the oldest cohort decreases the likelihood of the formation of a tie to a greater extent than their colleagues of the middle cohort.

Gender did not affect any of the sender and receiver relationships in the four instrumental networks.

\subsection{To what extent does being part of the same generational cohort affect the likelihood of engaging}

\section{in professional relationships?}

Regarding the effects of the relationship covariates, homophily effects can be found for the youngest cohort within all the networks. This finding suggests that school team members of the youngest cohort are more likely to form ties with colleagues of the same generational cohort than with colleagues of the middle or the oldest generational cohort. This tendency of homophily occurs at the level of significance for the youngest generational cohort in the networks of discussing work, asking advice, and collaboration. The other generational cohorts, middle cohort and oldest cohort, do not show a significant homophily effect in all the networks. Relationships in these cohorts can therefore be described as heterogeneous. We conclude that, in particular, school team members of the youngest cohort tend to form intra-generational ties, whereas older generational cohort members form inter-generational ties. 


\section{Conclusion and discussion}

In the present study we have focused on the role of being part of a generational cohort in the formation of professional relationships within elementary school teams in the Netherlands. Our first research question focused on differences between generational cohorts in terms of professional relationships being sent or received. To answer this question, we included both findings from descriptive ANOVA analysis of degree centrality measures, and from a $\mathrm{p} 2$ model based on probability distributions. The latter analysis gave a slightly different picture which we explain by the fact that our p2 model provides a more sophisticated investigation of sender and receiver tendencies within the networks. Therefore, we elaborate our conclusions primarily on the basis of this $\mathrm{p} 2$ model and indicate how they are in line with the ANOVA analyses.

When looking for differences in sending and receiving relationships, we noticed a significant role of generational cohort within the networks of asking advice, providing advice, and collaboration. Within the network of discussing work we did not find any significant impact of belonging to a certain generation, neither in the ANOVA and the $\mathrm{p} 2$ findings. Next, we discuss the findings for each of the respective networks studied.

Regarding asking and providing advice, our results reveal that the middle cohort can be seen as an important source of advice within the school team. This is the cohort who is asked by most colleagues for advice. On the other hand, we noticed that the oldest cohort sees themselves as an important provider of advice, since this cohort provides more colleagues with advice. It must be noticed that members of the oldest cohort provide advice to colleagues who did not necessarily ask for it. The middle cohort does not certainly provide more advice, but they are asked for it by more colleagues. This finding underlines the importance of the middle cohort as a source of knowledge within the school team. In addition, we found that the youngest cohort is provided with advice by more colleagues, as compared to their older counterparts. Relationships within the networks asking advice and providing advice can be interpreted as complementary. When looking at these networks asking and providing advice, it can be questioned to what extent providing advice is the result of asking advice. Further research might pay attention to what degree providing advice is a voluntary action or the result of being asked for advice. When looking to the effects of generational cohort within these two advice networks, we also recognize the complementary tendencies. Being part of the oldest cohort did decrease the likelihood of sending relationships for asking advice, and did increase the likelihood of sending relationships for providing advice. A second complementary tendency for asking and providing advice was found for the middle cohort. While being part of the middle cohort increased the likelihood of receiving relationships within the network asking advice, it decreased the likelihood of receiving relationships within the network of providing advice. Being part of the oldest cohort decreased the likelihood of being provided with advice even more than the middle cohort. The ANOVA results were supporting these findings, revealing that young school team members were more provided with advice than their oldest counterparts. A similar tendency has been observed by Spillane et al. (2012), where more experienced colleagues were less likely to receive advice. Our findings of both asking and providing advice relationships do relate to the traditional mentor models in which older or experienced teachers serve as knowledge providers to younger ones. Within recent developments and ideas on intergenerational learning, knowledge supplies and demands are seen as important for all generational cohorts. Consequently, our findings bring the importance of stimulating intergenerational relationships under attention.

Within the last network, collaboration, we found that being part of the oldest cohort did decrease the likelihood of receiving collaboration ties. A decrease of receiving collaboration relationships was also found for the middle cohort. These findings were also supported by the ANOVA results. The youngest cohort is the most preferred cohort to collaborate with. Previous research revealed that older teachers have positive perceptions towards their youngest counterparts in terms of enthusiasm and creativity (Geeraerts et al., 2016). These positive perceptions about young teachers might contribute to preference to collaborate with them. We found similarities within the tendencies of sending and receiving relationships between the providing advice network and collaboration network. This raises questions on the existence of overlap 


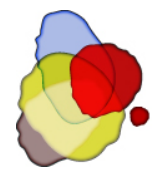

between both networks. Further research might investigate the extent to which instrumental relationships show overlap.

Whereas gender did not affect the likelihood to send or receive professional relationships, the other control variable function did. Principals tend to mention more different colleagues they prefer to collaborate with. In addition, principals were also chosen by more colleagues to discuss work with and to ask advice to. Further research might foreground the role of the school principal and investigate, for instance, the network position of the principal within professional school team networks, and, the role of the principal's age.

Regarding our first research question we conclude that, for some networks, generational cohorts based on chronological age do matter in the formation of professional relationships. These findings also underline the importance of focussing on different instrumental networks since different age dynamics can be at play, and therefore give support to the findings of Moolenaar (2010) to approach different professional networks as unique networks. Future research might include expressive relationships in addition to instrumental relationships, for instance, by including friendship relationships. By doing this, the extent to which instrumental relationships are explained by expressive relationships can be investigated.

Our second research question captured the mechanisms of homophily within elementary school teams. Teachers of the youngest cohort in particular seem to form relationships within their own generation for discussing work, asking advice, and collaboration, which is in line with the homophily effects for the young individuals in other contexts found by Marsden (1988). From the viewpoint of intergenerational learning and intergenerational knowledge sharing, this is a worrying finding. This suggests that facilitating bidirectional intergenerational relationships is important for practice. Further research, for instance by using qualitative methods, may dive deeper into the reasons why young teachers have this tendency. Factors such as the level of trust, a safe and respectful climate, as perceptions of being evaluated or hierarchical perceptions of seniority are worth taking into account. In addition, it is worth to investigate how this tendency of homophily relates to early career teacher dropout and challenges such as practice shock or feelings of uncertainty (Pillen, Beijaard, \& den Brok, 2013; Stokking, Leenders, De Jong, \& Van Tartwijk, 2003). Also, literature on intergenerational relationships often focusses on age bias and generational stereotyping within organizations (e.g. King \& Bryant, 2017; Rupp, Vodanovich, \& Credé, 2006). The effects of age stereotyping in school teams on the formation of professional relationships and intergenerational knowledge exchange might offer interesting starting points for further research.

This study has limitations that suggest additional paths for future research. First of all, sending and receiving advice ties are only general indicators of knowledge flows. The content of the advice ties has not been included in this study. Given the idea that teachers of different generations are able to provide different kinds of information and knowledge, it might be interesting to investigate content related advice relationships, for instance, whom do you go to for advice on classroom management? This will provide information on which knowledge can be seen as a demand or supply for a certain generational cohort. A second limitation is related to the fact that we did not have information about the amount of advice shared and the frequencies of interactions within the networks. An actor can receive more advice from one colleague than from a number of different colleagues. Further research can more explicitly map the strength of teacher relationships across generational cohorts by looking at the frequency, length, and duration of contact (e.g. Van Waes et al., 2015). Also, the relevance of the received advice has not been discussed yet; to what extent is provided advice valuable advice to a teacher? Exchange of information or advice is no guarantee for learning to occur. For instance Kyndt, Vermeire, and Cabus (2016) did not find a significant relationship of knowledge acquisition and access to information with informal workplace learning outcomes. This finding underlines the importance of further evaluating the relevance of the advice that is being shared (e.g. van der Rijt, Van den Bossche, van de Wiel, De Maeyer, Gijselaers, \& Segers, 2013; van der Rijt, Van den Bossche, van de Wiel, Segers, \& Gijselaers, 2012). Similarly, information on the quality of relationships between generational cohorts would be a valuable contribution for further research. This also opens up the discussion on the 'unknown side of intergenerational learning' which refers to the idea that intergenerational learning does not necessarily lead to positive learning outcomes. This is also connected to newly emerging 
social network research on 'negative ties'. An interesting perspective on knowledge sharing within school teams might be to investigate the opposite, for instance, knowledge hiding. Further research might focus on reasons why school team members would be shielding knowledge from their school team.

Previous research suggested not to use a too narrow approach on 'generation', but also to take into account factors such as work tenure and years of job experience (Geeraerts et al., 2016; Kooij, de Lange, Jansen, \& Dikkers, 2008). We did not include years of experience since this variable was too highly correlated with our age variable, which might cause problems of multicollinearity. We would argue that the conceptualisation of generations and operationalization of generations of teachers needs further elaboration. For instance, future research might focus on the relevance of age boundaries of generational cohorts or reveal whether there exists a linear effect of age? The division of generational cohort in this study was based on previous studies within the context of school teams (Edge, 2014; Geeraerts et al., 2016). In this study, our generational cohorts are diverse. For instance, the youngest cohort includes both inexperienced teachers in their induction phase and teachers with 10 years of experience. This division has not been included in this study, but potentially offers an important perspective to further unravel the complexity of teacher generations.

Due to the selection of our sample in which we targeted balance in terms of the presence of three generational cohorts within school teams, the generalizability of our study is limited to schools that are characterized by equal distribution of generational cohorts. An interesting path for further studies is to look at schools with different constellations of generational cohorts and examine whether these different constellations paint a similar picture regarding the formation of intergenerational relationships within school teams. Would our results remain if a certain generational cohort is absent within a school team? Differences in age demographic profiles of school teams might raise interesting questions for further research.

Also, our analysis technique (multilevel p2 modelling) has certain limitations since this model is restricted to dyadic relationships (Spillane et al., 2012). The extent to which relationships between pairs of teachers are influenced by their relationships within the larger structure of the network (e.g. triads) are not taken into account. Based on our findings, future studies might hypothesize more complex social network models and for instance use Exponential Random Graph Models (ERGM) to explore triadic structures in intergenerational relationships.

To conclude, we state that being part of a generational cohort based on chronological age does matter within these elementary school teams and that it plays a role in the formation of teachers' professional relationships. Both researchers and practitioners may regard social networks as a valuable concept to contextualise and investigate teacher interactions in order to further understand and support teacher intergenerational learning and teachers' professional development in general.

\section{Keypoints}

- Being part of a generational cohort affects the formation of relationships within the networks asking and providing advice, and collaboration.

- Different generation dynamics are at play within different networks.

- Young teachers are more likely to be mentioned as a preferred partner to collaborate with.

- Old teachers are less likely to ask advice, while teachers of the middle generation are more being asked for advice.

- Young teachers in particular tend to form relationships within their own cohort. 


\section{Acknowledgments}

We would like to thank prof. dr. Marijtje Van Duijn (University of Groningen, the Netherlands) for her helpful comments on our $\mathrm{p} 2$ model.

\section{References}

Argote, L., McEvily, B., \& Reagans, R. (2003). Managing knowledge in organizations: An integrative framework and review of emerging themes. Management Science, 49(4), 571-582. doi: $10.1287 / \mathrm{mnsc} .49 .4 .571 .14424$

Ashton, D. N. (2004). The impact of organisational structure and practices on learning in the workplace. International Journal of Training and Development, 8(1), 43-53. doi:10.1111/j.13603736.2004.00195.x

Baker-Doyle, K. (2015). No teacher is an island: how social networks shape teacher quality. In G. K. LeTendre \& A. W. Wiseman (Eds.), Promoting and sustaining a quality teacher workforce (International perspectives on education and society (Vol. 27, pp. 367-383).

Boer, P., Huisman, M., Snijders, T. A. B., Steglich, C., Wichers, L. H. Y., \& Zeggelink, E. P. H. (2006). StOCNET: An open software system for the advanced statistical analysis of social networks. Version 1.7. . Groningen: ICS/Science Plus.

Borgatti, S. P., Everett, M. G., \& Johnson, J. C. (2013). Analyzing social networks. London: SAGE Publications Ltd.

Brücknerová, K., \& Novotný, P. (2016). Intergenerational learning among teachers: overt and covert forms of continuing professional development. Professional Development in Education, 1-20. doi:10.1080/19415257.2016.1194876

Carolan, B. V. (2014). Social network analysis and education. Theory, methods \& applications. Los Angeles: Sage.

Choo, C. W. (1998). The knowing organization: How organizations use information to construct the meaning, create knowledge, and make decisions. New York, NY: Oxford University Press.

Cross, R., Parker, A., \& Borgatti, S. P. (2002). Making invisible work visible: using social network analysis to support strategic collaboration. California Management Review, 44(2), 25-46.

Daly, A. J. (2010). Social network theory and educational change. Cambridge: Harvard Education Press.

Dencker, J. C., Joshi, A., \& Martocchio, J. J. (2007). Employee benefits as context for intergenerational conflict. Human Resource Management Review, 17(2), 208-220. doi:10.1016/j.hrmr.2007.04.002

Doornbos, A. J., Bolhuis, S., \& Simons, P. R. J. (2004). Modeling work-related learning on the basis of intentionality and developmental relatedness: a noneducational perspective. Human Research Development Review, 3(3), 250-274. doi:10.1177/1534484304268107

Edge, K. (2014). A review of the empirical generations at work research: implications for school leaders and future research. School Leadership \& Management, 34(2), 136-155. doi:10.1080/13632434.2013.869206

Edge, K., Descours, K., \& Frayman, K. (2016). Generation X school leaders as agents of care: leader and teacher perspectives from Toronto, New York City and London. In K. Leithwood, J. Sun \& K. Pollock (Eds.), How school leaders contribute to student success: Springer International Publishing.

Eraut, M. (2004). Informal learning in the workplace. Studies in Continuing Education, 26(2), 247-273. doi: $10.1080 / 158037042000225245$

Feld, S. L. (1982). Social structural determinants of similarity among associates. American Sociological Review, 47(6), 797-801. Retrieved from http://www.jstor.org/stable/2095216

Fuller, A., \& Unwin, L. (2004). Young people as teachers and learners in the workplace: challenging the novice-expert dichotomy. International Journal of Training and Development, 8(1), 32-42. doi:10.1111/j.1360-3736.2004.00194.x 
Geeraerts, K., Vanhoof, J., \& Van den Bossche, P. (2016). Teachers' perceptions of intergenerational knowledge flows. Teaching and Teacher Education, 56 (May 2016), 150-161. doi: $10.1016 /$ j.tate. 2016.01 .024

Gerpott, F. H., Lehmann-Willenbrock, N., \& Voelpel, S. C. (2016). A phase model of intergenerational learning in organizations. Academy of Management Learning \& Education. doi:10.5465/amle.2015.0185

Glass, A. (2007). Understanding generational differences for competitive success. Industrial and Commercial Training, 39(2), 98-103. doi:10.1108/00197850710732424

Grangeat, M., \& Gray, P. (2007). Factors influencing teachers' professional competence development. Journal of Vocational Education \& Training, 59(4), 485-501. doi:10.1080/13636820701650943

Johnson, J. C. (1990). The primacy and potential of high school departments. In M. W. McLaughlin, J. E. Talbert \& N. Bascia (Eds.), The contexts of teaching in secondary schools (pp. 167-184). New York: Teachers College Press.

Kelchtermans, G. (2006). Teacher collaboration and collegiality as workplace conditions. A review. Zeitschrift für Pädagogik, 52(2), 220-237.

Kelchtermans, G., \& Ballet, K. (2002). The micropolitics of teacher induction. A narrative-biographical study on teacher socialisation. Teaching and Teacher Education, 18, 105-120.

King, S. P., \& Bryant, F. B. (2017). The workplace intergenerational climate scale (WICS): a self-report instrument measuring ageism in the workplace. Journal of Organizational Behavior, 38(1), 124-151. doi:10.1002/job.2118

Kooij, D., de Lange, A., Jansen, P., \& Dikkers, J. (2008). Older workers' motivation to continue to work: five meanings of age. A conceptual review. Journal of Managerial Psychology, 23(4), 364-394. doi:10.1108/02683940810869015

Kwakman, K. (2003). Factors affecting teachers' participation in professional learning activities. Teaching and Teacher Education, 9(2), 149-170. doi:10.1016/S0742-051X(02)00101-4

Kyndt, E., Vermeire, E., \& Cabus, S. (2016). Informal workplace learning among nurses. Organisational learning conditions and personal characteristics that predict learning outcomes. Journal of Workplace Learning, 28(7), 435-450. doi:10.1108/JWL-06-2015-0052

Lave, J., \& Wenger, E. (1991). Situated learning: legitimate peripherical participation. Cambridge: Cambridge University Press.

Lazega, E., \& van Duijn, M. (1997). Position in formal structure, personal characteristics and choices of advisors in a law firm: a logistic regression model for dyadic network data. Social networks, 19, 375397.

Lee, T., Fuller, A., Ashton, D. N., Butler, P., Felstead, A., Unwin, L., \& Walters, S. (2004). Workplace learning: main themes \& perspectives. Learning as Work Research Paper 2. University of Huddersfield.

Lin, N. (1999). Building a network theory of social capital. Connections, 22(1), 28-51.

Lohman, M. C. (2000). Environmental inhibitors to informal learning in the workplace: a case study of public school teachers. Adult Education Quarterly, 50(2), 83-101. doi:10.1177/07417130022086928

Lohman, M. C. (2006). Factors influencing teachers' engagement in informal learning activities. Journal of Workplace Learning, 18(3), 141-156. doi:10.1108/13665620610654577

Mannheim, K. (1952). Essays on the sociology of knowledge. London, UK: Routledge \& Kegan Paul.

Marsden, P. V. (1988). Homogeneity in confiding relations. Social networks, 10, 57-76.

Marsden, P. V. (2011). Survey methods for network data. In J. Scott \& P. J. Carringston (Eds.), The Sage handbook of social network analysis (pp. 310-388). Thousand Oaks, CA: Sage Publications.

McPherson, J. M., Smith-Lovin, L., \& Cook, J. M. (2001). Birds of a feather: Homophily in social networks. Annual review of sociology, 27, 415-444. doi: 10.1146/annurev.soc.27.1.415

Meredith, C., Van den Noortgate, W., Struyve, C., Gielen, S., \& Kyndt, E. (2017). Information seeking in secondary schools: a multilevel network approach. Social networks, 50, 35-45. doi:10.1016/j.socnet.2017.03.006

Moolenaar, N. M. (2010). Ties with Potential. Nature, antecedents, and consequences of social networks in school teams. (Doctoral dissertation), University of Amsterdam. 
Novotný, P., \& Brücknerová, K. (2014). Intergenerational learning among teachers: an interaction perspective. Studia paedagogica, 19(4). doi:10.5817/SP2014-4-3

Pillen, M., Beijaard, D., \& den Brok, P. (2013). Tensions in beginning teachers' professional identity development, accompanying feelings and coping strategies. European Journal of Teacher Education, 36(3), 240-260. doi:10.1080/02619768.2012.696192

Reagans, R., \& McEvily, B. (2003). Network structure and knowledge transfer: the effects of cohesion and range. Administrative Science Quarterly, 48(2), 240-267. doi:10.2307/3556658

Richter, D., Kunter, M., Klusmann, U., Lüdtke, O., \& Baumert, J. (2011). Professional development across the teaching career: Teachers' uptake of formal and informal learning opportunities. Teaching and Teacher Education, 27, 116-126. doi: 10.1016/j.tate.2010.07.008

Ropes, D. (2011). Intergenerational learning in organisations. A research framework. In CEDEFOP (Ed.), Working and ageing. Guidance and counselling for mature learners. Luxembourg: Publications Office of the European Union.

Ropes, D. (2013). Intergenerational learning in organizations. European Journal of Training and Development, 37(8), 713-727. doi:10.1108/EJTD-11-2012-0081

Rupp, D. E., Vodanovich, S. J., \& Credé, M. (2006). Age bias in the workplace: the impact of ageism and causal attributions. Journal of Applied Social Psychology, 36(6), 1337-1364. doi:10.1111/j.00219029.2006.00062.x

Sfard, A. (1998). On two metaphors for learning and the dangers of choosing just one. Educational Researcher, 27(2), 4-13. doi:10.3102/0013189X027002004

Spillane, J. P., Kim, C. M., \& Frank, K. A. (2012). Instructional advice and information providing and receiving behavior in elementary schools: exploring tie formation as a building block in social capital development. American Educational Research Journal, 49(6), 1112-1145. doi:10.3102/0002831212459339

Starks, A. (2013). The forthcoming generational workforce transition and rethinking organizational knowledge transfer. Journal of Intergenerational Relationships, 11, 223-237. doi:10.1080/15350770.2013.810494

Stokking, K., Leenders, F., De Jong, J., \& Van Tartwijk, J. (2003). From student to teacher: reducing practice shock and early dropout in the teaching profession. European Journal of Teacher Education, 26(3), 329-350. doi:10.1080/0261976032000128175

Tajfel, H., \& Turner, J. C. (1986). The social identity theory of intergroup behavior. In S. Worchel \& W. G. Austin (Eds.), Psychology of intergroup relations (pp. 7-24). Chicago, IL: Nelson-Hall.

Thambi, M., \& O'Toole, P. (2012). Applying a knowledge management taxonomy to secondary schools. School Leadership \& Management, 32(1), 91-102. doi:10.1080/13632434.2011.642350

Tynjälä, P. (2008). Perspectives into learning at the workplace. Educational Research Review, 3, 130-154. doi:10.1016/j.edurev.2007.12.001

Van Duijn, M., \& Vermunt, J. K. (2006). What is special about social network analysis? Methodology, 2(1), 2-6. doi:10.1027/1614-1881.2.1.2

van der Rijt, J., Van den Bossche, P., van de Wiel, M. W. J., De Maeyer, S., Gijselaers, W. H., \& Segers, M. S. R. (2013). Asking for help: a relational perspective on help seeking in the workplace. Vocations and learning, 6, 259-279. doi:10.1007/s12186-012-9095-8

van der Rijt, J., Van den Bossche, P., van de Wiel, M. W. J., Segers, M., \& Gijselaers, W. H. (2012). The role of individual and organizational characteristics in feedback-seeking behaviour in the initial career stage. Human Research Development International, 15(3), 283-301. doi:10.1080/13678868.2012.689216

van Knippenberg, D., De Dreu, K. K. W., \& Homan, A. C. (2004). Work group diversity and group performance: an integrative model and research agenda. Journal of Applied Psychology, 89(6), 10081022. doi:10.1037/0021-9010.89.6.1008

Van Waes, S., Van den Bossche, P., Moolenaar, N. M., De Maeyer, S., \& Van Petegem, P. (2015). Knowwho? Linking faculty's networks to stages of instructional development. Higher Education, 70(5), 807826. doi:10.1007/S10734-015-9868-8 
Wasserman, S., \& Faust, K. (1994). Social network analysis: Methods and applications. New York: Cambridge University Press.

Williams, K. Y., \& O'reilly, C. A. (1998). Demography and diversity in organizations: A review of 40 years of research. Research in Organizational Behavior, 20, 77-140.

Wolff, C. E., van den Bogert, N., Jarodzka, H., \& Boshuizen, H. P. A. (2015). Keeping an eye on learning: Differences between expert and novice teachers' representations of classroom management events. Journal of Teacher Education, 66(1), 68-85. doi:10.1177/0022487114549810

Zijlstra, B. J. H., \& van Duijn, M. A. J. (2003). Manual p2. Version 2.0.0.7. Groningen: iec ProGAMMA/University of Groningen.

Zijlstra, B. J. H., Van Duijn, M. A. J., \& Snijders, T. A. B. (2006). The multilevel p2 model: A random effects model for the analysis of multiple social networks. Methodology, 2(1), 42-47. doi:10.1027/16141881.2.1.42 